\title{
RANDOM STRATEGY VERSUS TECHNICAL ANALYSIS STRATEGY IN THE US MARKET
}

\author{
Miroslav Svoboda ${ }^{1}$ \\ Martina Sponerová ${ }^{2}$
}

DOI: https://doi.org/10.31410/ITEMA.2020.121

\begin{abstract}
Random strategy is currently an interesting alternative to traditional trading of financial instruments. The paper builds on existing research into the trading of investment instruments through random strategy and strategies based on technical analysis. The highly liquid USD/CAD currency pair was chosen for the US market research. We analyze five years of data, and in every intraday trading session, only a single position will be opened. Technical analysis strategy uses essential indicators such as Bollinger Bands, relative strength index (RSI), moving averages (MA) and other. Every trading position will have the risk-reward ratio (RRR) 3 to 1. In addition, another trading positions on the USD/CAD currency pair will be opened without technical analysis. The time of entry into position will be indicated randomly with a similar risk-reward ratio (RRR) 3 to 1. The aim of this paper is to assess which of the above strategies is more suitable for the investor. In other words, this paper aims to compare the strategy of technical analysis and the random strategy in intraday trading concerning the profitability of these trades. We expect that a random strategy will be more suitable for the investor in many points.
\end{abstract}

Keywords: Investment decisions, Foreign exchange markets, Moving average, Backtesting, US market, Relative strength index.

\section{INTRODUCTION}

Technical analysis, together with fundamental analysis, ranks among the basic analyzes in trading on financial markets. This paper extends the knowledge gained from the data presented in the authors' paper entitled RANDOM STRATEGY VERSUS TECHNICAL ANALYSIS STRATEGY: THE CASE OF EUR / USD INTRADAY TRADING to American markets. The authors deal with the comparison of trading strategies of technical analysis and trading strategies based on market randomness. The use of technical analysis has been presented in many disgusting publications in Taylor and Allen (1992), Menkhoff (1997), Lui and Mole (1998), Oberlechner (2001), Gehrig and Menkhoff (2004) and Menkhoff and Taylor (2007).

There are studies that contain large amounts of trading position data based on technical analysis indicators. For example, the study by Hsu and Taylor (2013) and Coakley, Marzano and Nankervis (2016) deals with testing technical analysis in the foreign exchange market using the SPA test. The study reports a very low rate of profitability of trading positions based on some indicators of technical analysis. Zarrabi, Snaith and Coakley (2017) used FDR analysis

\footnotetext{
1 Masaryk University, Faculty of Economics and Administration, Department of Finance, Lipová 41a, 603 00 Brno, Czech Republic

2 Masaryk University, Faculty of Economics and Administration, Department of Finance, Lipová 41a, 603 00 Brno, Czech Republic
} 
in their study and found that the predictive power of technical analysis is possible. The study used data for 20 years when the trading strategy had to be updated at least once a month, otherwise the predictive ability of technical analysis is not sustainable in the long run.

Following the above study, a trading strategy in foreign exchange markets based on technical analysis is not sustainable in the long term. However, some studies report the profitability of technical analysis when trading in foreign exchange markets. These are, for example, the studies of Sweeney 1986, Levich and Thomas, 1993, Neely, 1997, LeBaron, 1999, 2002. A study by Sager and Taylor, 2006, Menkhoff and Taylor, 2007 examines the efficiency of the foreign exchange market with respect to small investors influencing the market. Small investors are also important for our research, because our strategies are based on use for small investors. According to the authors, there is a lot of space for further knowledge and studies in this segment.

This paper builds on the authors' long-term research in the field of random strategy in combination with a strategy based on technical analysis. The paper aims to test selected strategy based on technical analysis and compare the results with simple random strategy for US market. The authors used a long period to obtain additional information on the research.

\section{METHODOLOGY AND DATA}

In this article, the authors identified two investment strategies. These strategies have been applied to the foreign exchange market of the USD / CAD currency pair, which reflects the US Market. The strategy (SMA/RSI strategy) based on technical analysis uses the Simple Moving Average (SMA) indicator together with the Relative Strength Index (RSI) indicator. The strategy based on randomness (Random strategy) does not use any indicator of technical analysis.

For backtesting, we choose currency pair, with regard to the US market, USD/CAD from $1 / 2 / 2015$ to $12 / 23 / 2019$. Trading positions were determined with a Risk-reward-ratio (RRR) of 1 to 3. Trading positions therefore showed a profit of 60 pips or a loss of 20 pips from the opening price of each position. Both sell and buy orders were used in the research. Due to the fact that the research compared 2 investment strategies on the same currency pair, it was not necessary to include fees in the research data. If we included the fees in the dataset, it would be 1-2 pips for each position. The amount of the fee, of course, depends on the specific service provider. The following Table 1 shows the basic characteristics of our analysis.

Table 1. Basic characteristics of both strategies

\begin{tabular}{|l|l|l|}
\hline & \multicolumn{1}{|c|}{ Term } & \multicolumn{1}{c|}{ Value } \\
\hline $\mathbf{1 .}$ & $\bullet$ Currency pair & $\bullet$ USD/CAD \\
\hline $\mathbf{2 .}$ & $\bullet$ Time frame & $\bullet \mathrm{H} 1$ \\
\hline $\mathbf{3 .}$ & $\bullet$ Period & $\bullet 1 / 2 / 2015-12 / 23 / 2019$ \\
\hline $\mathbf{4 .}$ & $\bullet$ Currency of the account & $\bullet$ USD \\
\hline $\mathbf{5 .}$ & $\bullet$ Demonstrative account value & $\bullet 10000$ USD \\
\hline $\mathbf{6 .}$ & $\bullet$ RRR & $\bullet 3 / 1$ \\
\hline $\mathbf{7 .}$ & $\bullet$ Profit (target) & $\bullet 60$ pips \\
\hline $\mathbf{8 .}$ & $\bullet$ Loss (stop loss) & $\bullet 20$ pips \\
\hline $\mathbf{9 .}$ & $\bullet$ Time zone & $\bullet$ UTC +1 \\
\hline
\end{tabular}

Source: Author's calculations 


\section{1 SMA/RSI STRATEGY}

A simple moving average (SMA) is usually used to determine the trend. It is a popular indicator of technical analysis for many investors. The calculation of a given indicator is calculated as the arithmetic average of the asset price for a certain period. A period of 250 weeks was used in the research. We have incorporated another indicator of technical analysis into our strategy, namely the relative strength index. The relative strength index is a momentum oscillator, which determines the change and speed of price movements. The conditions for buying a position were defined by a price increase above 250 SMA and at the same time a movement of RSI (25) above 0.7 (70). The conditions for the sale of the currency were defined by a price drop below 250 SMA and at the same time a movement of RSI (25) below 0.3 (30). In this research, we used the trend following strategy, where these investors expect/believe that when the price rises, it will grow even more and vice versa.

Our SMA/RSI strategy is summarized in Table 2.

Table 2. Characteristics of SMA/RSI strategy

\begin{tabular}{|c|l|l|}
\hline & \multicolumn{1}{|c|}{ Term } & \multicolumn{1}{c|}{ Value } \\
\hline 1. & - Signal to buy & $\begin{array}{l}\text { - First closed candle after candle rise } \\
\text { above SMA }(250) \text { and a movement of RSI } \\
(25) \text { above } 0,7\end{array}$ \\
\hline 2. & - Signal to sell & $\begin{array}{l}\text { First closed candle after candle drops } \\
\text { below SMA }(250) \text { and a movement of RSI } \\
(25) \text { below } 0,3\end{array}$ \\
\hline 3. & - Close position & $\bullet$ Breakthrough stop loss or target \\
\hline
\end{tabular}

Source: Author's calculations

The following Figure 1 demonstrates the signal to open the position (buy position in this example) and signal to close the position for our SMA/RSI strategy (breakthrough target).

Figure 1. Signal to buy, close position - USD/CAD

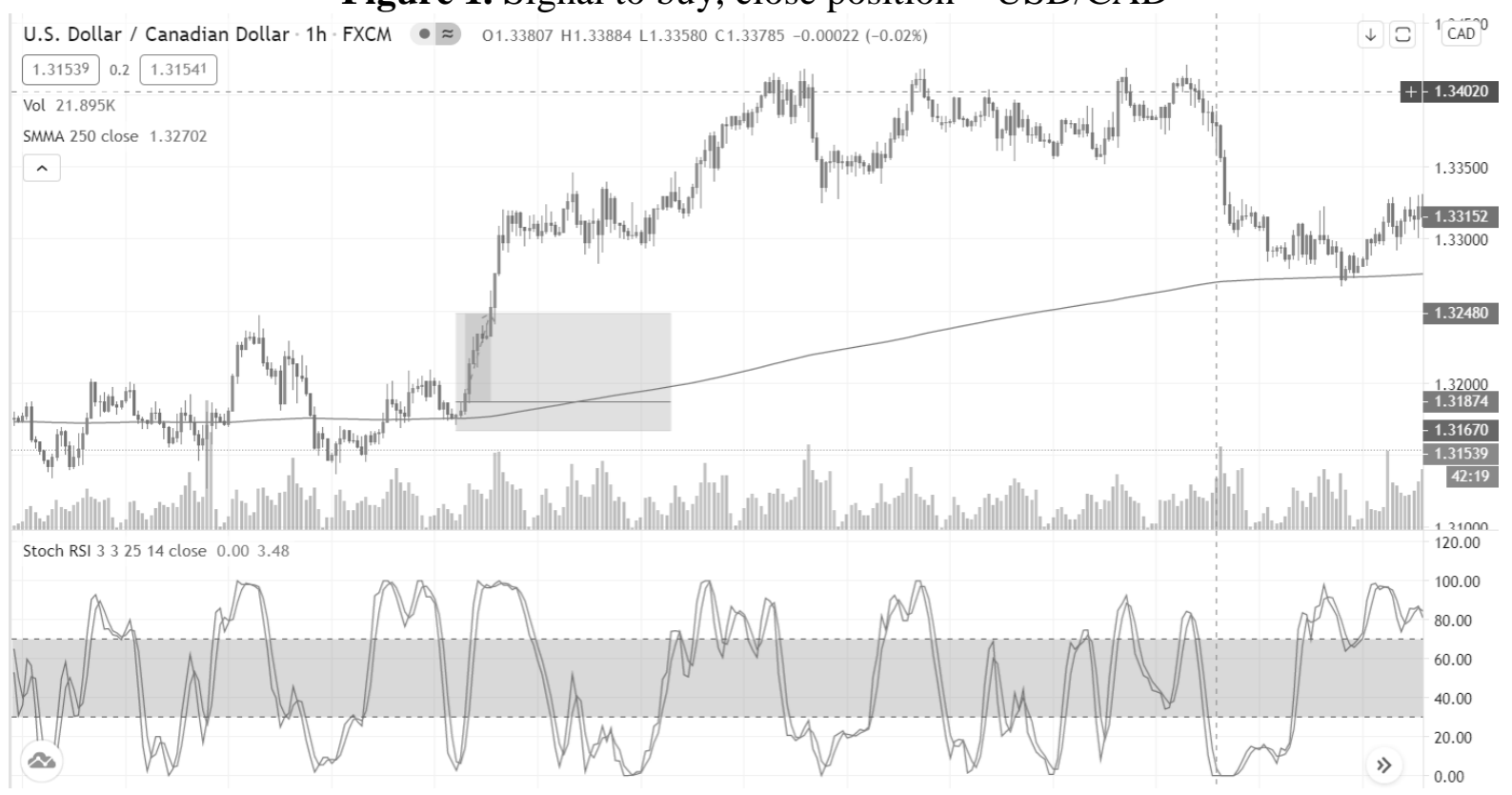

Source: Author's calculations, tradingview.com 


\section{2 RANDOM STRATEGY}

Our random strategy is based on trading without technical and fundamental analysis. We choose random parameters to enter trading positions. Trading positions are executed at 2 p.m. $(\mathrm{UTC}+1)$ every trading day. The designated hour to enter the position predicted a higher rate of traders entering the market due to the early opening hour for the US Market. The determination of the long or short position was programmed randomly (50:50).

Table 3 shows the basic characteristics of the random strategy:

Table 3. Characteristics of Random strategy

\begin{tabular}{|c|l|l|}
\hline & \multicolumn{1}{|c|}{ Term } & \multicolumn{1}{|c|}{ Value } \\
\hline 1. & $\bullet$ Signal to buy & $\begin{array}{l}\bullet \text { Random on a daily basis at the } \\
\text { selected time (14:00, UTC }+1)\end{array}$ \\
\hline 2. & • Signal to sell & $\begin{array}{l}\bullet \text { Random on a daily basis at the } \\
\text { selected time }(14: 00, \text { UTC }+1)\end{array}$ \\
\hline 3. & $\bullet$ Close position & $\bullet$ Break through stop loss or target \\
\hline
\end{tabular}

Source: Author's calculations

The figure below illustrates a trading position according to a random strategy. This is a selling position where the position was opened according to the selected time and in this case the stop loss was terminated.

Figure 2. 14:00, UTC +1 , sell position (at random), close position

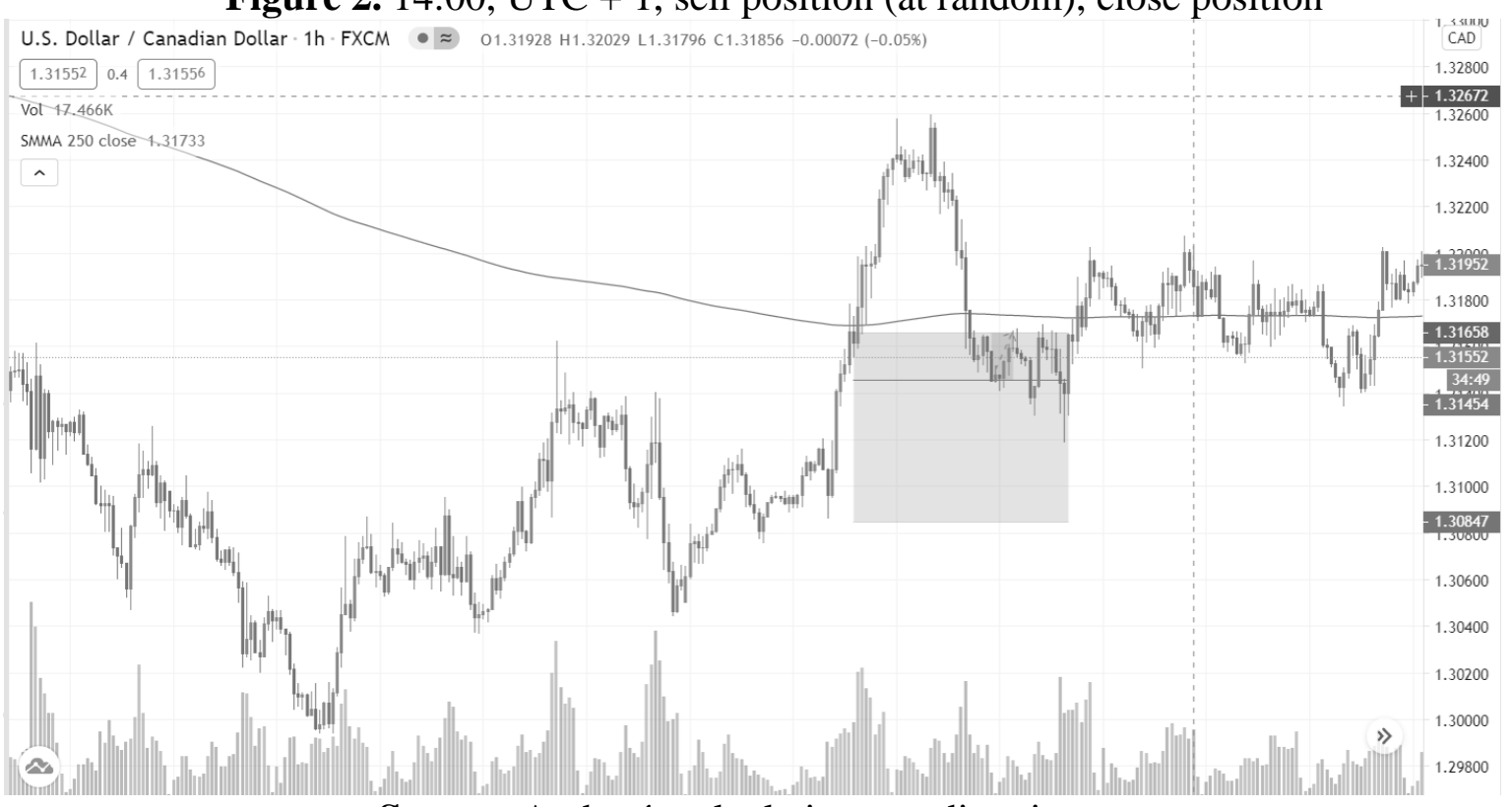

Source: Author's calculations, tradingview.com

\section{RESULTS AND DISCUSSION}

We use almost 5 years of data and backtest our strategies presented in the previous Chapter 1 . In Table 4, our results for both strategies are presented. The random strategy opened one position every trading day, and it resulted in 1296 positions in total. For SMA/RSI strategy we have 1163 observations. 
Table 4. Results

\begin{tabular}{|c|l|l|}
\hline & \multicolumn{1}{|c|}{ SMA/RSI strategy } & \multicolumn{1}{c|}{ Random strategy } \\
\hline Number of open positions & $\bullet 1163$ & $\bullet 1296$ \\
\hline Number of long positions & $\bullet 604$ & $\bullet 663$ \\
\hline $\begin{array}{c}\text { \% of success - long } \\
\text { positions }\end{array}$ & $\bullet 21,36$ & $\bullet 24,59$ \\
\hline Number of short positions & $\bullet 559$ & $\bullet 633$ \\
\hline $\begin{array}{c}\text { \% of success - short } \\
\text { positions }\end{array}$ & $\bullet 22,9$ & $\bullet 24,33$ \\
\hline $\begin{array}{c}\text { Number of profitable } \\
\text { positions (60 pips profit) }\end{array}$ & $\bullet 257$ & $\bullet 317$ \\
\hline $\begin{array}{c}\text { \% of profitable positions } \\
\text { (60 pips profit) }\end{array}$ & $\bullet 22,1$ & $\bullet 24,46$ \\
\hline $\begin{array}{c}\text { Number of loss positions (20 } \\
\text { pips loss) }\end{array}$ & $\bullet 906$ & $\bullet 979$ \\
\hline $\begin{array}{c}\text { \% of loss positions (20 pips } \\
\text { loss) }\end{array}$ & $\bullet 77,9$ & $\bullet 75,54$ \\
\hline \% total profit/loss & $\bullet-23,4$ & $\bullet-5,34$ \\
\hline Total profit/loss & $\bullet-2340,91$ & $\bullet-534,24$ \\
\hline
\end{tabular}

Source: Author's calculations

The Random strategy was less loss-making in our research. In this case, the strategy for the investor performed better than the strategy based on technical analysis. The research builds on our previous research on strategies based on technical analysis versus random strategy. In the case of the SMA strategy of the EUR/USD currency pair, this strategy, based on technical analysis, showed almost double the percentage of profit in the same trading account. A random strategy also had similar results. Previously, we also examined another GBP/USD currency pair, which showed similarly profitable results as the mentioned EUR/USD pair, with the difference that a random strategy was more profitable.

Figure 3. Total loss SMA/RSI strategy

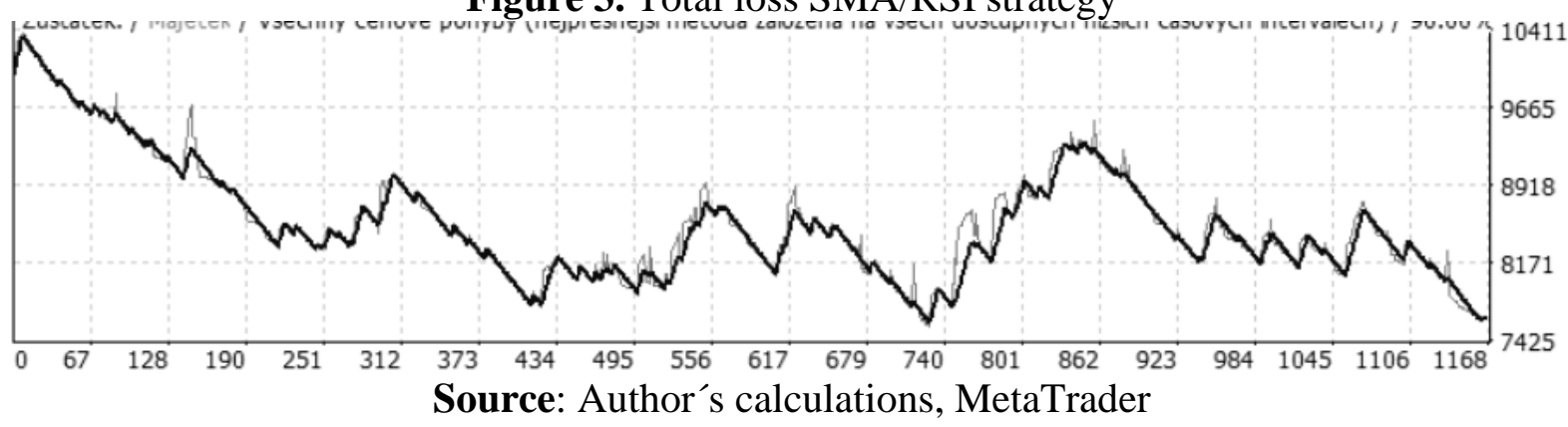

Figure 4. Total loss Random strategy

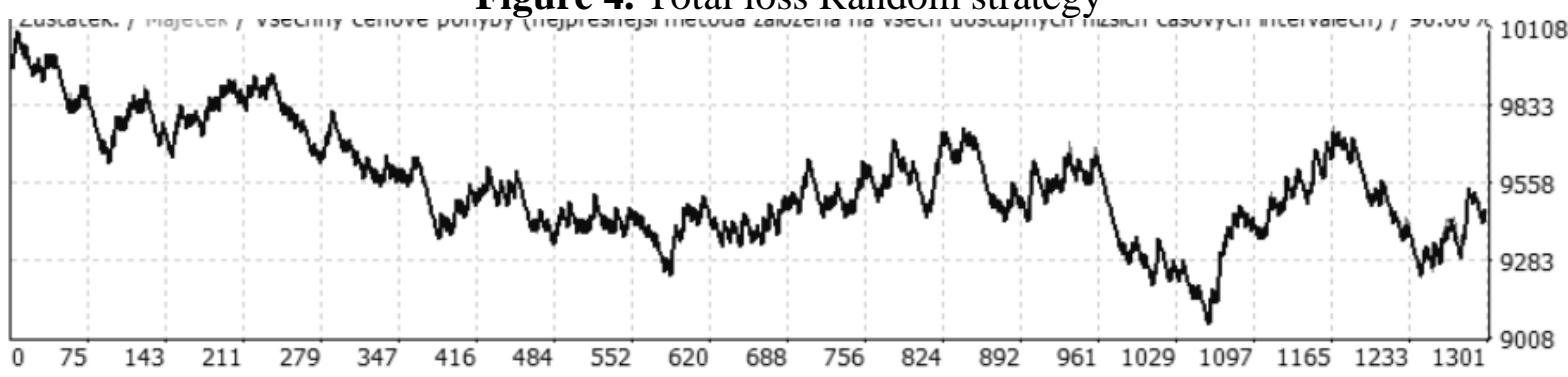

Source: Author's calculations, MetaTrader 


\section{FUTURE RESEARCH DIRECTIONS}

With the ever-evolving research of technical analysis strategies versus random strategies, we gain important knowledge in terms of investment decisions of small investors trading in currency markets. The data obtained show us that a random strategy can show better results than a strategy based on technical analysis. The question is therefore whether it is necessary for the investor to use complex strategies based on technical analysis or to use randomness, of course, provided that money management and RRR are complied with. Another question is whether the random strategy we present only works in currency markets or we can apply it to other markets, such as the commodity market, stocks, etc. These questions predispose us to further research in the field of financial markets.

\section{CONCLUSION}

Two trading strategies were addressed in the submitted paper. The first strategy was based on technical analysis indicators. Specifically, it was a joint use of SMA and RSI indicators. The second strategy was random. This means that only one position was opened each day, randomly at the chosen time. The trading strategies have been tested on the USD / CAD currency pair for almost 5 years. Subsequently, both strategies were compared and the results from the obtained data were evaluated.

In this case, both strategies ended in a loss. However, the random strategy showed a loss significantly lower than the loss based on technical analysis indicators. Thus, an important question arises as to whether a random strategy in the event of an unfavorable market situation is not safer than a strategy based on technical analysis. Therefore, it is important in the future to apply these strategies to situations where market developments do not support indicators based on technical analysis. The results presented in this paper build on the authors' previous research and prove that there is a high potential for further research in this segment. It is mainly an examination of other investment instruments and also research into the effectiveness of both approaches in creating trading strategies.

\section{ACKNOWLEDGMENT}

This research was supported by the Masaryk University internal grant MUNI/A/1081/2019.

\section{REFERENCES}

Coakley, J. \& Marzano, M. \& Nankervis, J. (2016). How profitable are FX technical trading rules?. International Review of Financial Analysis, vol. 45, pp. 273-282.

Gehrig, T., \& Menkhoff, L. (2004). The use of flow analysis in foreign exchange: Exploratory evidence. Journal of International Money and Finance, vol. 23, pp. 573-594.

Hsu, P. H., \& Taylor, M. P. (2013). Forty years, thirty currencies and 21,000 trading rules: A large-scale, data-snooping robust analysis of technical trading in the foreign exchange market. Working paper, thirty currencies and 21.

Laïdi, A. (2008). Currency Trading And Intermarket Analysis. 1nd ed. Wiley Trading, pp. 279.

LeBaron, B. (1999). Technical trading rule profitability and foreign exchange intervention. Journal of International Economics, vol. 49, pp. 125-143.

LeBaron, B. (2002). Technical trading profitability in foreign exchange markets in the 1990s. Working paper, Brandeis University. 
Levich, R. M., \& Thomas, L. R. (1993). The significance of technical trading-rule profits in the foreign exchange market: A bootstrap approach. Journal of International Money and Finance, vol. 12 (5), pp. 451-474.

Lui, Y. H., \& Mole, D. (1998). The use of fundamental and technical analysis by foreign exchange dealers: Hong Kong evidence. Journal of International Money and Finance, vol. 17 , pp. 535-545.

Menkhoff, L. (1997). Examining the use of technical currency analysis. International Journal of Finance and Economics, vol. 2(4), pp. 307-318.

Menkhoff, L., \& Taylor, M. P. (2007). The obstinate passion of foreign exchange professionals: Technical analysis. Journal of Economic Literature, vol. 45, pp. 936-972.

Neely, C. J. (1997). Technical analysis in the foreign exchange market: A layman's guide. Federal Reserve Bank of St. Louis Review, vol. 79(5), pp. 23-38.

Oberlechner, T. (2001). Importance of technical and fundamental analysis in the European foreign exchange market. International Journal of Finance and Economics, vol. 6(1), pp. 81-93.

Taylor, M. P., \& Allen, H. (1992). The use of technical analysis in the foreign exchange market. Journal of International Money and Finance, vol. 11, pp. 304-314.

Sager, M. J., \& Taylor, M. P. (2006). Under the microscope: The structure of the foreign exchange market. International Journal of Finance and Economics, vol. 11, pp. 81-95.

Sweeney, R. J. (1986). Beating the foreign exchange market. Journal of Finance, vol. 41(1), pp. 163-182.

Wilder, J. W. (1978). New concepts in technical trading systems. Trend Research, McLeansville, NC.

Zarabi, N. \& Snaith, S. \& Coakley, J. (2017). FX technical trading rules can be profitable sometimes!. International Review of Financial Analysis, vol. 49, pp. 113-127. 